www.nature.com/ja

\title{
A pair of sulfur-containing geldanamycin analogs, 19-S-methylgeldanamycin and 4,5-dihydro- 19-S-methylgeldanamycin, from Streptomyces hygroscopicus 17997
}

\author{
Xin Liu', Jingyan $\mathrm{Li}^{1}$, Siyang $\mathrm{Ni}$, Linzhuan Wu, Hongyuan Wang, Ling Lin, Weiqing He and Yiguang Wang
}

The Journal of Antibiotics (2011) 64, 519-522; doi:10.1038/ja.2011.39; published online 11 May 2011

Keywords: 4,5-dihydro-19-S-methylgeldanamycin; 19-S-methylgeldanamycin; Streptomyces hygroscopicus 17997

Geldanamycin (GDM, Figure 1) is a benzoquinone ansamycin produced by Streptomyces hygroscopicus. ${ }^{1-3}$ It is a specific inhibitor of human heat shock protein 90 (Hsp90), which is a molecular chaperone assisting in protein folding, cell signaling and tumor repression, and a potential cellular target for anti-tumor agent. GDM is only used as a promising lead compound for anti-cancer drug development because of its poor water solubility and severe liver toxicity. ${ }^{4-6}$

Although hundreds of semi-synthetic GDM analogs had been developed by chemical synthesis, ${ }^{7-10}$ a total of only tens of GDM analogs had been created by genetic manipulation of GDM biosynthetic gene cluster, ${ }^{11-15}$ and a few were discovered as natural GDM analogs. ${ }^{16-18}$ There is still an urgent need for novel GDM analog(s) with improved pharmacological profile and lower hepatotoxicity in developing new anti-cancer agent targeting Hsp90.

We are interested in discovering novel natural/biosynthetic GDM analog(s) with improved pharmacological profile(s). In our search for GDM analog(s), we found that Streptomyces hygroscopicus 17997, a GDM producer isolated by Institute of Medicinal Biotechnology, Chinese Academy of Medical Sciences, ${ }^{6}$ produced a red compound after the maximal GDM accumulation in fermentation broth. We detected also a similar red compound in the fermenation broth of the $g d m P$ (encoding a cytochrome P450 monooxygenase for C4,5 oxidation of the post-polyketide synthase tailoring process in GDM biosynthesis)-disrupted mutant of S. hygroscopicus 17997, a 4,5dihydrogeldanamycin producer. ${ }^{19}$ The two red compounds were proved by us to be a pair of sulfur-containing GDM analogs, with chemical structures of 19-S-methylgeldanamycin (1) and 4,5-dihydro19-S-methylgeldanamycin (2), respectively, (Figure 1). In this note, we report the discovery, isolation, structure elucidation and some physicochemical properties of $\mathbf{1}$ and $\mathbf{2}$.

Stock-frozen spores of S. hygroscopicus 17997 were thawed and spread onto ISPII $(0.4 \%$ yeast extract, $1.0 \%$ malt extract, $0.4 \%$ glucose, $1.5 \%$ agar power) plates, incubated at $28{ }^{\circ} \mathrm{C}$ for $8-10$ days for mycelium growth and sporulation, then a slice of the seed culture was picked up and inoculated into a fermentation medium $(2 \%$ starch, $0.5 \%$ cotton seed power, $0.5 \%$ glucose, $1.0 \%$ cornsteep liquor, $0.5 \%$ yeast powder, $0.2 \% \mathrm{CaCO}_{3}$ ) for shaking ( 200 r.p.m.) at $28^{\circ} \mathrm{C}$ for $120-144 \mathrm{~h}$. The fermentation supernatant was used for subsequent detection and/or isolation of $\mathbf{1}$.

The fermentation supernatant of S. hygroscopicus 17997, with a culture time of $120-144 \mathrm{~h}$, was extracted with an equal volume of EtOAc. The organic layer was concentrated, then subjected to silica gel TLC for a chromatograph (developed with a mobile phase of EtOAc/ $\mathrm{CH}_{2} \mathrm{Cl}_{2} /$ hexane/MeOH, 9:6:6:1, v/v). A red band with a $R_{\mathrm{f}}=0.30$ (for $\left.\mathrm{GDM}, R_{\mathrm{f}}=0.54\right)$ appeared. The red band changed to blue upon spraying $2.0 \mathrm{moll}^{-1} \mathrm{NaOH}$ (Figure 2), a color reaction for the preliminary discrimination of GDM and its analogs. ${ }^{20}$ Compound(s) within the red band of silica TLC plate was eluted out by EtOAc, dried and then dissolved in $\mathrm{MeOH}$ for LC-ESI(+)-MS analysis. In the LC, a major elution peak appeared, with its UV absorption profile similar to that of GDM (Supplementary Figure S1). In MS ${ }^{1}$, the major elution peak contained a principal molecular ion with $m / z=629.4 \mathrm{Da}\left([\mathrm{M}+\mathrm{Na}]^{+}\right.$, compound 1$)$, whose fragment ions dispayed a $\mathrm{MS}^{2}$ pattern typical of GDM analogs, ${ }^{21}$ (Supplementary Figure S2). On the basis of these data, we believed that 1 was an analog of GDM.

Key Laboratory of Biotechnology of Antibiotics of Ministry of Health, Institute of Medicinal Biotechnology, Chinese Academy of Medical Sciences \& Peking Union Medical College, Beijing, China

1These authors contributed equally to this work.

Correspondence: Professor L Wu, Key Laboratory of Biotechnology of Antibiotics of Ministry of Health, Institute of Medicinal Biotechnology, Peking Union Medical College \& Chinese Academy of Medical Sciences, Tiantan Xili, Beijing 100050, China.

E-mail: wulinzhuan@yahoo.com.cn

Received 15 October 2010; revised 8 April 2011; accepted 12 April 2011; published online 11 May 2011 

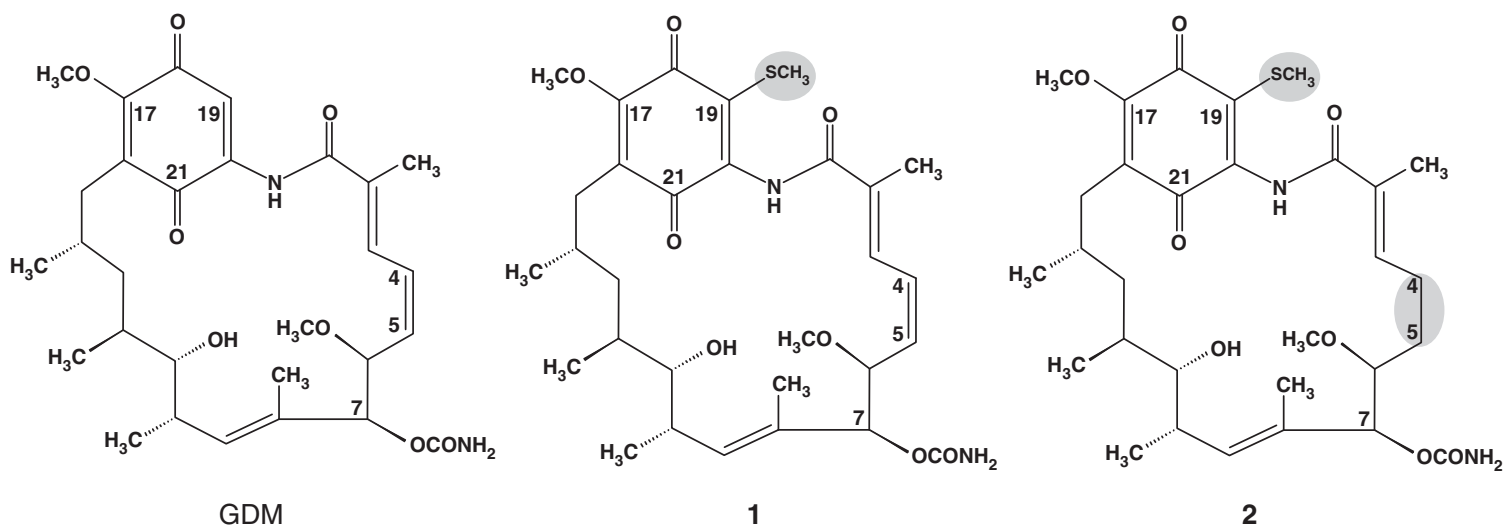

Figure 1 The chemical structures of GDM, 1 and 2.

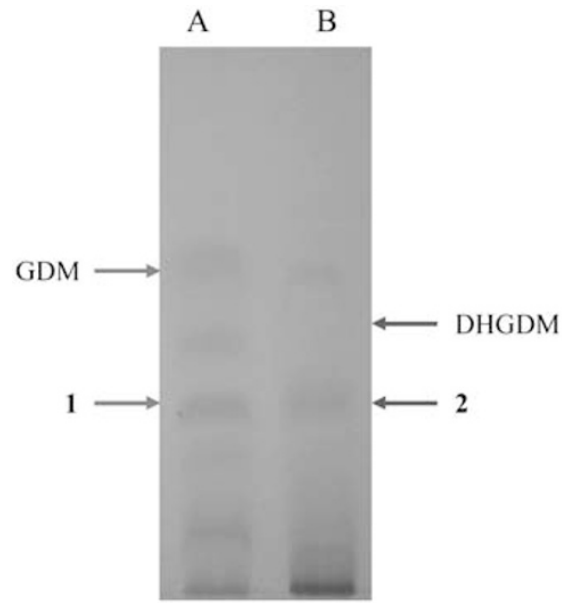

before color reaction

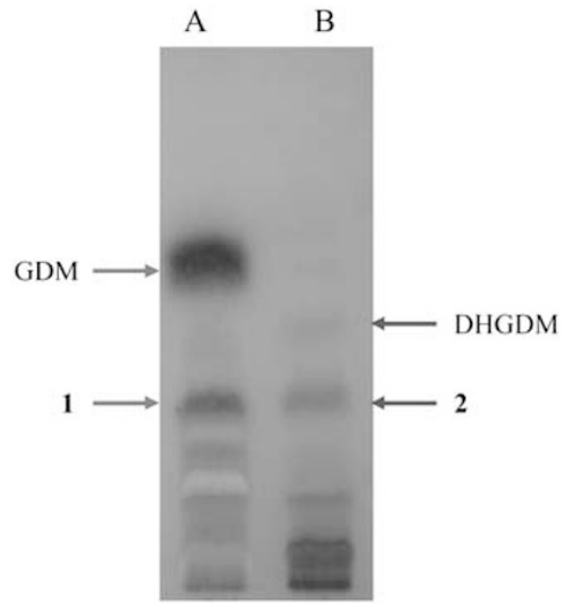

after color reaction

Figure 2 Silica gel TLC of EtOAc extracts of fermentation supernatant of Streptomyces hygroscopicus 17997 (A) and its gdmP-disrupted mutant (B).

1 was then purified for chemical structure elucidation. An equal volume of EtOAc was used to extract the fermentation supernatant of S. hygroscopicus 17997 , then dried to a crude solid by rotary evaporation at room temperature. After fractionation by silica gel chromatography $(\varphi 2.5 \times 80 \mathrm{~cm})$, the pool containing 1 (eluted by $\mathrm{CH}_{2} \mathrm{Cl}_{2}-$ $\mathrm{MeOH}, 9: 1, \mathrm{v} / \mathrm{v}$ ) was dried and then re-dissolved in $\mathrm{MeOH}$ for preparative Sephadex LH-20 fractionation $(\varphi 1.5 \times 100 \mathrm{~cm})$, obtaining the refined preparation of 1 . This refined preparation was used for preparative HPLC (Shimadzu LC-10AT $v$, Shimadzu International Trading Co., Ltd, Beijing, China; Agilent ZorBax SB-C18, Agilent Technologies Co. Ltd, Beijing, China, $5 \mu \mathrm{m}, \varphi 9.4 \times 250 \mathrm{~mm}, \mathrm{MeOH} /$ water, $\left.45: 55(\mathrm{v} / \mathrm{v}), 1.5 \mathrm{ml} \mathrm{min}^{-1}\right)$, yielding a pure preparation of 1 (purity $\geqslant 96 \%$, calculated by area $\%$ of HPLC analysis at $254 \mathrm{~nm}$ ). From 10.3-1 fermentation supernatant, we obtained $10 \mathrm{mg}$ pure preparation of compound $\mathbf{1}$ as amorphous red powder. It was used for HR-ESI(+)-MS, elemental (sulfur) analysis, ${ }^{1} \mathrm{H}$ - and ${ }^{13} \mathrm{C}-\mathrm{NMR}$ analyses and so on.

HR-ESI(+)-MS indicated that $\mathbf{1}$ had an accurate mass of 629.25688 $\left([\mathrm{M}+\mathrm{Na}]^{+}\right)$. The elemental analysis showed 1 containing $\sim 5.16 \%$ sulfur, suggesting that $\mathbf{1}$ has a sulfur atom in its molecule (cald.: $5.28 \%$, without $\mathrm{Na}^{+}$). Therefore, the molecular formula of 1 was deduced to be $\mathrm{C}_{30} \mathrm{H}_{42} \mathrm{O}_{9} \mathrm{~N}_{2} \mathrm{~S}$ (exact mass, $[\mathrm{M}+\mathrm{Na}]^{+} 629.25087$ ).

The ${ }^{1} \mathrm{H}$ - and ${ }^{13} \mathrm{C}-\mathrm{NMR}$ spectra of $\mathbf{1}$ showed strong similarities to those of GDM, but an additional methyl signal (H: $\delta 2.58, \mathrm{C}: \delta 16.9)$ appeared. Considering its chemical shift $\left(\delta_{\mathrm{C}}\right.$ 16.9) and a sulfur atom in 1 , the additional methyl signal was deduced to be as a $-\mathrm{SCH}_{3}$ group. The HMBC data suggested correlations between the $\mathrm{H}$ of $-\mathrm{SCH}_{3}$ and aromatic quaternary $\mathrm{C}-19$ ( $\delta$ 130.7), indicating that the $-\mathrm{SCH}_{3}$ was connected to the benzoquinone ring through C-19. Therefore, the chemical structure of 1 was determined to be 19-S-methylgeldanamycin. The NMR chemical shifts of $\mathbf{1}$ were assigned completely from HSQC, COSY and HMBC (Table 1, Figure 3).

The discovery, isolation and purification of 2 from the $g d m P$ disrupted mutant of S. hygroscopicus 17997 was made or carried out in a very similar way as that of $\mathbf{1}$ from S. hygroscopicus 17997. From 43-1 fermentation supernatant of the $g d m P$-disrupted mutant, we obtained $68 \mathrm{mg}$ pure preparation of 2 (purity $\geqslant 98 \%$, calculated by area\% of HPLC analysis at $254 \mathrm{~nm}$ ).

2 was also an amorphous red powder, with an accurate mass of $631.26481\left([\mathrm{M}+\mathrm{Na}]^{+}\right)$by HR-ESI(+)-MS. 2 contained $5.00 \%$ sulfur by elemental analysis, suggesting also one sulfur atom in the molecule (cald.: 5.26\%, without $\mathrm{Na}^{+}$). Therefore, the molecular formula of 2 was deduced to be $\mathrm{C}_{30} \mathrm{H}_{44} \mathrm{~N}_{2} \mathrm{O}_{9} \mathrm{~S}$ (exact mass, $[\mathrm{M}+\mathrm{Na}]^{+}, 631.26652$ ), which is two hydrogen atoms more than that of $\mathbf{1}$. As $\mathbf{2}$ came from the gdmP-disrupted mutant of $S$ hygroscopicus 17997, a 4,5-dihydrogeldanamycin producer, the chemical structure of 2 was regarded as, most probably, 4,5-dihydro-19-S-methylgeldanamycin. 
The ${ }^{1} \mathrm{H}$ - and ${ }^{13} \mathrm{C}-\mathrm{NMR}$ spectra of 2 showed strong similarities to those of 1 , except for C-4,5 and their hydrogens. In the ${ }^{13} \mathrm{C}-\mathrm{NMR}$, two additional carbon signals of $\mathrm{CH}_{2^{-}}$at $\delta_{\mathrm{C}} 24.3$ and $\delta_{\mathrm{C}} 31.4$ appeared in 2 , whereas the carbon signals of $\mathrm{CH}-4\left(\delta_{\mathrm{C}} 130.0\right)$ and $\mathrm{CH}-5\left(\delta_{\mathrm{C}} 131.7\right)$

Table 1 NMR data of 1 and 2 in $\mathrm{CD}_{3} \mathrm{OD}$

\begin{tabular}{|c|c|c|c|c|}
\hline \multirow[b]{2}{*}{ Position } & \multicolumn{2}{|c|}{1} & \multicolumn{2}{|c|}{2} \\
\hline & $\delta_{C}$ & $\delta_{H}$ & $\delta_{C}$ & $\delta_{H}$ \\
\hline 1 & 175.9 & - & 176.3 & - \\
\hline 2 & 140.1 & - & 135.7 & - \\
\hline 3 & 125.4 & $6.39(1 \mathrm{H})$ & 135.1 & $5.70(1 \mathrm{H})$ \\
\hline \multirow[t]{2}{*}{4} & 130.0 & $6.41(1 \mathrm{H})$ & 24.3 & $1.99(1 \mathrm{H})$ \\
\hline & & & & $2.25(1 \mathrm{H})$ \\
\hline \multirow[t]{2}{*}{5} & 131.7 & $5.26(1 \mathrm{H})$ & 31.4 & $1.17(1 \mathrm{H})$ \\
\hline & & & & $1.21(1 \mathrm{H})$ \\
\hline 6 & 76.8 & $3.99(1 \mathrm{H})$ & 81.0 & $3.06(1 \mathrm{H})$ \\
\hline 7 & 82.8 & $4.89(1 \mathrm{H})$ & 82.1 & $4.93(1 \mathrm{H})$ \\
\hline 8 & 130.0 & - & 130.8 & - \\
\hline 9 & 136.0 & $5.20(\mathrm{H})$ & 134.1 & $5.12(1 \mathrm{H})$ \\
\hline 10 & 36.5 & $2.24(1 \mathrm{H})$ & 36.2 & $2.29(1 \mathrm{H})$ \\
\hline 11 & 73.4 & $3.54(1 \mathrm{H})$ & 73.9 & $3.59(1 \mathrm{H})$ \\
\hline 12 & 81.2 & $2.87(1 \mathrm{H})$ & 81.4 & $3.21(1 \mathrm{H})$ \\
\hline \multirow[t]{2}{*}{13} & 32.3 & $0.72(1 \mathrm{H})$ & 33.2 & $0.80(1 \mathrm{H})$ \\
\hline & & $1.57(1 \mathrm{H})$ & & $1.66(1 \mathrm{H})$ \\
\hline 14 & 30.4 & $2.08(1 \mathrm{H})$ & 30.6 & $2.05(1 \mathrm{H})$ \\
\hline \multirow[t]{2}{*}{15} & 30.6 & $2.43(1 \mathrm{H})$ & 30.4 & $2.38(1 \mathrm{H})$ \\
\hline & & $2.56(1 \mathrm{H})$ & & $2.64(1 \mathrm{H})$ \\
\hline 16 & 130.4 & - & 130.4 & - \\
\hline 17 & 158.9 & - & 159.2 & - \\
\hline 18 & 180.7 & - & 180.7 & - \\
\hline 19 & 130.7 & - & 132.0 & - \\
\hline 20 & 136.0 & - & 130.8 & - \\
\hline 21 & 182.9 & - & 183.0 & - \\
\hline $22\left(2-\mathrm{CH}_{3}\right)$ & 14.3 & $1.89(3 \mathrm{H})$ & 13.7 & $1.72(3 \mathrm{H})$ \\
\hline $23\left(6-\mathrm{OCH}_{3}\right)$ & 56.7 & $3.09(3 \mathrm{H})$ & 56.9 & $3.29(3 \mathrm{H})$ \\
\hline $24\left(7-\mathrm{OCONH}_{2}\right)$ & 159.1 & - & 159.0 & - \\
\hline $25\left(8-\mathrm{CH}_{3}\right)$ & 13.0 & $1.37(3 \mathrm{H})$ & 12.7 & $1.40(3 \mathrm{H})$ \\
\hline $26\left(10-\mathrm{CH}_{3}\right)$ & 18.8 & $0.94(3 \mathrm{H})$ & 18.2 & $0.98(3 \mathrm{H})$ \\
\hline $27\left(12-\mathrm{OCH}_{3}\right)$ & 56.6 & $3.25(3 \mathrm{H})$ & 59.4 & $3.39(3 \mathrm{H})$ \\
\hline $28\left(14-\mathrm{CH}_{3}\right)$ & 19.5 & $0.57(3 \mathrm{H})$ & 18.5 & $0.53(3 \mathrm{H})$ \\
\hline $29\left(17-\mathrm{OCH}_{3}\right)$ & 61.7 & $3.98(3 \mathrm{H})$ & 61.6 & $3.97(3 \mathrm{H})$ \\
\hline $30\left(19-\mathrm{SCH}_{3}\right)$ & 16.9 & $2.58(3 \mathrm{H})$ & 16.9 & $2.51(3 \mathrm{H})$ \\
\hline
\end{tabular}

${ }^{1} \mathrm{H}$ - and ${ }^{13} \mathrm{C}$-NMR spectra were obtained at 500 and $100 \mathrm{MHz}$, respectively, on INOVA-501 with TMS as internal standard, and measured in $\mathrm{CD}_{3} \mathrm{OD}$ at room temperature. in 1 missed in 2. In the ${ }^{1} \mathrm{H}-\mathrm{NMR}$, two pairs of $\mathrm{CH}_{2}$ - hydrogen signals $\left(\delta_{\mathrm{H}} 1.99 / 2.25, \delta_{\mathrm{H}} 1.17 / 1.21\right)$ appeared in 2 , whereas the two hydrogen signals of $\mathrm{CH}-4\left(\delta_{\mathrm{H}} 6.41\right)$ and $\mathrm{CH}-5\left(\delta_{\mathrm{H}} 5.26\right)$ in 1 disappeared in 2. Therefore, the chemical structure of 2 was determined to be 4,5dihydro-19-S-methylgeldanamycin. The NMR chemical shifts of $\mathbf{2}$ were assigned completely from HSQC, COSY and HMBC (Table 1).

We are not clear how the $-\mathrm{SCH}_{3}$ group is added onto GDM or 4,5dihydrogeldanamycin. Okabe $\mathrm{T}^{22}$ reported that naphthomycin A could react in vitro with a variety of - $\mathrm{SH}$-containing compounds by replacing the $-\mathrm{Cl}$ with a $-\mathrm{SR}$ (including $-\mathrm{SCH}_{3}$ ) at $\mathrm{C}-30$. Some hindered amines could also undergo addition reaction in vitro at C19- of GDM nonenzymatically. ${ }^{7,8}$ Several sulfur-containing ansamycins, such as thiazinotrienomycin, trierixin, 3-methylthiorifamycin SV and thiazorifamycins, naphthomycins I and $\mathrm{J}$, and awamycin ${ }^{23-28}$ had been isolated from Micromonospora sp. or Streptomyces sp. Of them, trierixin, 3-methylthiorifamycin $\mathrm{SV}$, and awamycin had a $-\mathrm{SCH}_{3}$ group in their molecule. Up to now, the production mechanisms of these sulfurcontaining groups of ansamycins remain unclear. Chemical and/or enzymatic reaction(s) may have taken place in their formation processes.

Cysyk $\mathrm{RL}^{29}$ reported that GDM could react chemically (that is, nonenzymatically) with glutathione (GSH), forming a GSH adduct, in which the thiol group of GSH is substituted in the 19-position of the benzoquinone ring of GDM. It is well known that GSH had an important role in the detoxification of reactive drugs (such as alkylating agents) and reactive metabolites formed by hepatic drugmetabolizing enzymes. Thus, blocking of the C-19 of GDM by a $-\mathrm{SCH}_{3}$ group may disrupt its reaction with GSH (and/or, possibly, the cysteines of some proteins within human cells), therefore reducing its toxicity to cells with lower GSH concentrations. Hence, $\mathbf{1}$ or $\mathbf{2}$ may show a different toxicological profile to GDM.

In a review about Hsp90 inhibitors, Janin $\mathrm{YL}^{30}$ suggested that thioether at C19- of GDM was a possible choice of GDM derivatization. We performed a molecular docking of GDM, 1 or $\mathbf{2}$ with human Hsp90 by SYBYL (Tripos, a Certara Company, St Louis, MO, USA), which gave CScore of 8.22, 7.65 or 7.77 for GDM, 1 or 2, suggesting that both 1 and 2 may still keep fairly high affinities for Hsp90 (CScore is an algorithm to estimate the binding affinity of a given protein-

Table 2 Solubility and cytotoxicity of 1 and 2

\begin{tabular}{lcc}
\hline Compound & Solubility $\left(\left.\mu \mathrm{g} \mathrm{m}\right|^{-1}\right)$ & $I C_{50}\left(\left.\mu \mathrm{mol}\right|^{-1}\right)$ \\
\hline GDM & 2.0 & 0.062 \\
$\mathbf{1}$ & 2019 & 19 \\
$\mathbf{2}$ & 2132 & 23 \\
\hline
\end{tabular}
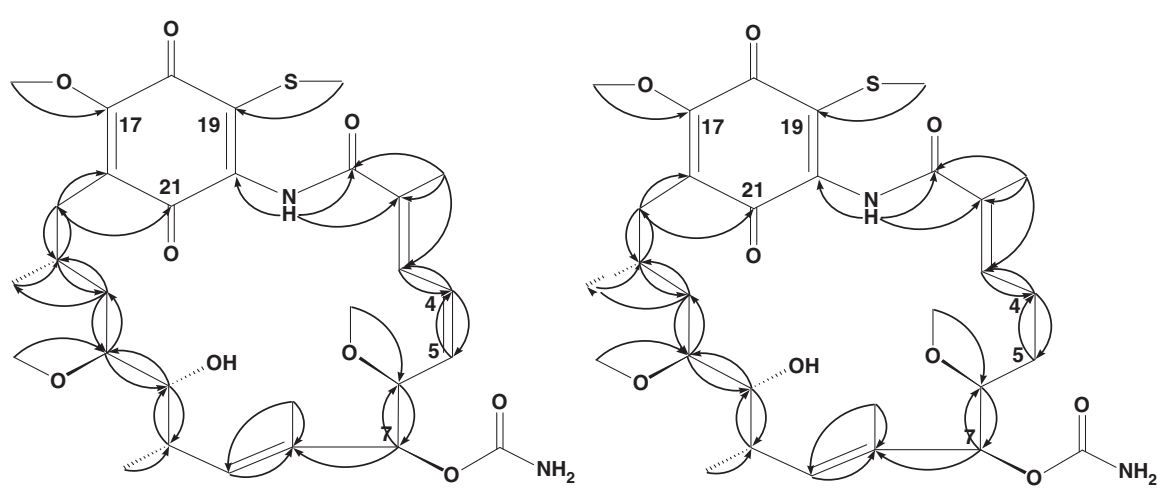

Figure 3 Key long-range correlations of $\mathbf{1}$ and $\mathbf{2}$ in $\operatorname{HMBC}\left({ }^{1} \mathrm{H} \rightarrow{ }^{13} \mathrm{C}\right)$. 
ligand complex, with a known three-dimensional structure). Therefore, we performed a preliminary test for the cytotoxicity of $\mathbf{1}$ or $\mathbf{2}$ against HepG2 cancer cell line, assayed by sulforhodamine B assay. ${ }^{31}$ Both 1 and 2 displayed decreased, but still very strong, cytotoxicities against HepG2 cancer cells (Table 2), but a comprehensive evaluation against different cancer cell lines is needed to appraise the cytotoxicity of $\mathbf{1}$ or $\mathbf{2}$ in the future.

We assayed the aqueous solubility of $\mathbf{1}$ or $\mathbf{2}$ in sodium chloride injection solution, following the method of $\mathrm{Li}$ et al. ${ }^{31}$ Compared with GDM, both 1 and 2 showed approximately 1000-fold increases (Table 2), suggesting that $\mathbf{1}$ and $\mathbf{2}$ should have significant improvements in bioavailability and pharmacokinetic properties. Besides, both 1 and $\mathbf{2}$ showed better light stability than that of GDM (Supplementary Figure S3), hence, they may have the potentials as anti-cancer drug candidates for further studies.

\section{ACKNOWLEDGEMENTS}

We are very grateful to Professor Zhuorong Li for providing pure GDM preparation, Dr Kaihuan Ren and Dr Wuli Zhao for providing HepG2 cells and Ms Hong Yi for performing molecular docking. This work was supported by National S\&T Major Special Project on Major New Drug Innovation (Item Numbers: 2009ZX09501-008, 2009ZX09301-003), and National Natural Science Foundation of China (Grant No. 30801447).

1 Sasaki, K., Rinehart, K. L. Jr, Slomp, G., Grostic, M. F. \& Olson, E. C. Geldanamycin. I. Structure assignment. J. Am. Chem. Soc. 92, 7591-7593 (1970).

2 Johnson, R. D., Haber, A. \& Rinehart, K. L. Jr Geldanamycin biosynthesis and carbon magnetic resonance. J. Am. Chem. Soc. 96, 3316-3317 (1974).

3 BeBoer, C. \& Dietz, A. The description and antibiotic production of Streptomyces hygroscopicus var. Geldanus. J. Antibiot. (Tokyo) 29, 1182-1188 (1976).

4 Rascher, A. et al. Cloning and characterization of a gene cluster for geldanamycin production in Streptomyces hygroscopicus NRRL 3602. FEMS Microbiol. Lett. 218, 223-230 (2003).

5 Neckers, L. Hsp90 inhibitors as novel cancer chemotherapeutic agents. Trends. Mol. Med. 8(4 Suppl), S55-S61 (2002).

6 Supko, J. G., Hickman, R. L., Grever, M. R. \& Malspeis, L. Preclinical pharmacologic evaluation of geldanamycin as an antitumor agent. Cancer Chemother Pharmacol. 36, 305-315 (1995)

7 Schnur, R. C. et al. erbB-2 Oncogene inhibition by geldanamycin derivatives: synthesis, mechanism of action, and structure-activity relationships. J. Med. Chem. 38, 3813-3820 (1995).

8 Schnur, R. C. et al. Inhibition of the oncogene product p185erbB-2 in vitro and in vivo by geldanamycin and dihydrogeldanamycin derivatives. J. Med. Chem. 38, 3806-3812 (1995).
9 Le Brazidec, J. Y. et al. Synthesis and biological evaluation of a new class of geldanamycin derivatives as potent inhibitors of Hsp90. J. Med. Chem. 47, 3865-3873 (2004).

10 Tian, Z. Q. et al. Potent cytotoxic C-11 modified geldanamycin analogues. J. Med. Chem. 52, 3265-3273 (2009).

$11 \mathrm{Kim}, \mathrm{W}$. et al. Rational biosynthetic engineering for optimization of geldanamycin analogues. Chembiochem 10, 1243-1251 (2009).

12 Buchanan, G. O. et al. Production of 8-demethylgeldanamycin and 4,5-epoxy-8demethylgeldanamycin from a recombinant strain of Streptomyces hygroscopicus. J. Nat. Prod. 68, 607-6010 (2005).

13 Vetcher, L. et al. Rapid engineering of the geldanamycin biosynthesis pathway by Red/ET recombination and gene complementation. Appl. Environ. Microbiol. 71, 1829-1835 (2005).

14 Eichner, S., Floss, H. G., Sasse, F. \& Kirschning, A. New, highly active nonbenzoquinone geldanamycin derivatives by using mutasynthesis. Chembiochem 10, 1801-1805 (2009).

$15 \mathrm{Hu}, \mathrm{Z}$. et al. Isolation and characterization of novel geldanamycin analogues. J. Antibiot. (Tokyo) 57, 421-428 (2004).

16 Zhang, H., Sun, G. Z., Li, X., Pan, H. Y. \& Zhang, Y. S. A new geldanamycin analogue from Streptomyces hygroscopicus. Molecules 15, 1161-1167 (2010).

17 Takatsu, T., Ohtsuki, M., Muramatsu, A., Enokita, R. \& Kurakata, S. I. Reblastatin, a novel benzenoid ansamycin-type cell cycle inhibitor. J. Antibiot. (Tokyo) 53, 1310-1312 (2000).

18 Stead, P. et al. Discovery of novel ansamycins possessing potent inhibitory activity in a cell-based oncostatin M signalling assay. J. Antibiot. (Tokyo) 53, 657-663 (2000).

19 Lin, L., He, W.Q. \& Wang, Y.G. A new 19-O-glycylated GDM in gdmP mutant of Streptomyces hygroscopicus 17997. in 15th International Symposium on the Biology of Actinomycetes, Shanghai, China, Abstract Book P51 (2009).

$20 \mathrm{Liu}, \mathrm{A}$. M. et al. A color reaction method for early preliminary discrimination of benzenic ansamycins [in Chinese]. Chin. J. Antibiot. 33, 403-406 (2008).

$21 \mathrm{Ni}, \mathrm{S}$. et al. Analysis of geldanamycin analogues in trace amounts by LC-MS/MS [in Chinese]. Chin. J. Biotechnol 25, 847-853 (2009).

22 Okabe, T. et al. Interaction of naphthomycin A with sulfhydryl compounds. J. Antibiot. (Tokyo) 39, 316-317 (1986).

23 Celmer, W. D., Sciavolino, F. C., Cullen, W. P. \& Routien, J. B. Mixture of antibiotics produced by new species of Micromonospora. US Patent 4062944 (1977).

24 Cricchio, R., Antonini, P. \& Sartori, G. Thiazorifamycins. III. Biosynthesis of rifamycins $\mathrm{P}, \mathrm{Q}$, and Verde, novel metabolites from a mutant of Nocardia mediterranea. J. Antibiot. (Tokyo) 842-846 (1980).

25 Hooper, A. M. \& Rickards, R. W. 3-Amino-5-hydroxybenzoic acid in antibiotic biosynthesis. XI. Biological origins and semisynthesis of thionaphthomycins, and the structures of naphthomycins I and J. J. Antibiot. (Tokyo) 51, 845-851 (1998).

26 Funayama, S. et al. Structure of awamycin, a novel antitumor ansamycin antibiotic. J. Antibiot. (Tokyo) 1284-1286 (1985).

27 Hosokawa, N. et al. Thiazinotrienomycins, new ansamycin group antibiotics. J. Antibiot. (Tokyo) 48, 471-478 (1995).

28 Futamura, Y. et al. Trierixin, a novel inhibitor of ER stress-induced XBP1 activation from Streptomyces sp. II. structure elucidation. J. Antibiot. (Tokyo) 60, 582-585 (2007).

29 Cysyk, R. L. et al. Reaction of geldanamycin and C17-substituted analogues with glutathione: product identifications and pharmacological implications. Chem. Res. Toxicol. 19, 376-381 (2006).

30 Janin, Y. L. Heat shock protein 90 inhibitors. A text book example of medicinal chemistry? J. Med. Chem. 48, 7503-7512 (2005).

$31 \mathrm{Li}$, Y. Y., He, W.Q., Wang, Y. G. \& Shao, R.G. A new post-PKS modification process in the carbamoyltransferase gene inactivation strain of Streptomyces hygroscopicus 17997. J. Antibiot. (Tokyo) 61, 347-355 (2008).

Supplementary Information accompanies the paper on The Journal of Antibiotics website (http://www.nature.com/ja) 